\title{
INFORMATION DEFICIENCY AMONG FARMERS REGARDING VEGETABLE PRODUCTION PRACTICES IN PERI-URBAN AREAS OF THE PUNJAB-PAKISTAN
}

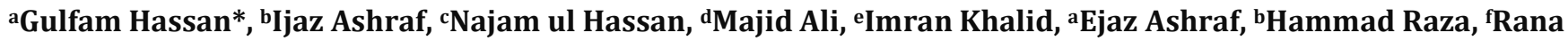 \\ T. Husnain, bShafiq-ur-Rehman Zia, bSalman Asghar \\ ${ }^{a}$ Department of Agricultural Extension, College of Agriculture, University of Sargodha-Pakistan. \\ ${ }^{b}$ Institute of Agricultural Extension, Education and Rural Development, University of Agriculture, Faisalabad-Pakistan. \\ ${ }^{c}$ Pest Warning and Quality Control of Pesticide, Bahawalpur-Pakistan. \\ ${ }^{d}$ Pest Warning and Quality Control of Pesticide, Rahim Yar Khan-Pakistan. \\ e Islamia University Bahawalpur, Pakistan. \\ $f$ Department of Horticulture, University of Agriculture Faisalabad.
}

\section{ART ICLE INFO}

\section{Article History}

Received: January 18, 2020

Revised: March 12, 2020

Accepted: April 27, 2020

\section{Keywords}

Vegetable production Information deficiency

Fertilizer application

Information needs

Production practices

\section{A B S T R A C T}

This study aimed at exploring the information deficiency among vegetables growers regarding production practices of vegetables. Total 208 vegetable growers, who were selected randomly participated in the study as respondents. The data were collected on structured questionnaire through face-to-face interview technique. The analysis of the data indicated that the farmers had diverse demographic conditions, but primarily with ordinary level of education (52.4\% were illiterate), small land holdings and over reliance on farming sources to generate income $(77.9 \%)$. Cultivation of vegetables was observed on small land holdings whereas $87 \%$ aimed at not only commercializing the produce abut also meet the domestic needs. In order to meet information needs, important for the vegetable's cultivation, neighbour farmers were the most preferred information source (59.61\%) while agriculture department $(10.57 \%)$ and agriculture helpline $(8.48 \%)$ were the least. Farmers had high level of information deficiency regarding Fertilizer application $(\overline{\mathrm{x}}=4.38)$, Seed rate $(\bar{x}=4.25)$, Insect's pests/diseases identification (4.01) and medium level deficiency regarding selection of Varieties $(\bar{x}=3.87)$, Insects pets management $(\bar{x}=3.53)$ and Harvesting $(\bar{x}=3.51)$. This is affirmed that farmers had information deficiency about the major aspects of the production and it could have impacted the production inversely. Farmers had more inclination towards traditional information sources and this could be the reason of information deficiency among farmers. This study urges more proactive role of agricultural extension department to mainstream the information delivery mechanism for the timely access and uniform delivery of required information among vegetable growers.

Corresponding Author: Gulfam Hassan

Email:g.h.gullz@gmail.com

(C) The Author(s) 2021.

\section{INTRODUCTION}

Balanced human diet is a prerequisite for health, and vegetables supply the food nutrients needed for the balanced human diet. Vegetables provide both macro and micro food nutrients (Otitoju et al., 2014) Vegetables also play a pivotal role by combating different disease, lowering cholesterol level and reducing accumulation of carcinogenic substance 
(Stangeland et al., 2009). Being an essential component of human diet, vegetables are consumed all over the world to have a reduced risk of some chronic diseases. Sufficient vegetables consumption may reduce the heart diseases to $23 \%$. For example, blood cancer, diabetes and cancer can easily be cured by using vegetables like peas and cucumber. Similarly, green beans are helpful in reducing sugar and cholesterol level in blood (Rao and Rao, 2007).

By increasing consumption of fruits and vegetables, lives of about 2.7 million people could be saved each year. In under-developed countries where the people are suffering from different chronic diseases (obesity, cancer, diabetes, heart diseases etc.) and are deficient in vitamins and minerals, the intake of minimum $400 \mathrm{~g}$ of fruits and vegetables per day can be helpful to fulfil their nutritional requirements for a healthy existence (Knapton, 2014). In Pakistan, government recommends an intake of $0.83 \mathrm{~kg}$ of onion, $0.38 \mathrm{~kg}$ of tomatoes, and $1.54 \mathrm{~kg}$ of other vegetables per capita on monthly basis (Government of Pakistan, 2012). The cultivation area containing vegetables such as onion, garlic and chilies was 0.381 million hectares (which is about $1.67 \%$ of the total cropped area), producing more than 4.06 million tons of vegetables annually. There has been an increasing demand of these vegetables with every passing day for domestic consumption in the form of raw and cooked food in rural and urban areas. In these days, vegetables are not being used merely for cooking purposes but many valuable commodities such as pickles, soups, ketchup, sauces, chutney and salads are the daily used products of these vegetables (Memon, 2013).

Vegetables are the short duration crops and are acceptable in all farming systems. However, due to increasing pressure on food and cash crops the area under vegetable production in Pakistan is limited to only 3.1 percent $(0.62 \mathrm{mh})$ of the total cropped area (Khokhar, 2014). More than thirty-six varieties of vegetables are grown on large scale in Pakistan (Government of Pakistan, 2006). The major vegetables grown in the country are potato, onion, chilies, tomato, turnip, okra, carrot, cauliflower, peas and tinda gourd, covering $78 \%$ of the total area under vegetables (Government of Pakistan, 2012). Among different provinces of Pakistan, Punjab holds the largest share of 63 and 74 percent in vegetables' area and production, respectively (Shaheen et al., 2011). The area under vegetable cultivation in the Punjab is 367,000 hectares having major vegetables like potato, turnip, carrot, peas, tinda and cauliflower (Khokhar, 2014).

Because of population pressure, vegetables' consumption is increasing but, so far, per capita intake is below the level recommended by World Health Organization. This situation solemnly points the need to increase vegetables production (Hall et al., 2009). In Pakistan, to meet the demands, production of vegetables is not enough which results in high prices (Adil et al., 2012). There is double increase in the growth of urban population than that of total growth. Asian countries are leading in this regard (Department of Economic and Social Affairs, 212). Due to their perishability, vegetable commodities have received greater attention and in developing world they are produced closer to their consumption area. Vegetable production has thus become concentrated in peri-urban zones in Asia (Midmore and Jansen, 2003). In Pakistan fruit and vegetable markets have been established by the cities and towns to utilize the supply from the nearby areas. Government of Pakistan has thus decided to establish fruit and vegetable zones in big cities like Karachi, Faisalabad, Multan, Swat and Quetta where more than thirty-six varieties of vegetables are grown (Government of Pakistan, 2006).

The countries where farmers have small landholdings, vegetable production provides them opportunity for intensive production resulting to increased participation in the market (Adil et al., 2007). Literature review depicts that drought, pest attack, fertilizer shortage and high price of fuel for pumping ground water were the major problems observed by the farming community of Eastern Ethiopia for vegetable production. The quality of produce was also deteriorated as the farmers were lacking in knowledge regarding production of vegetables (Gebru et al., 2017). This indicates that information and knowledge regarding management of vegetables is indispensable because the deficiency of information can harm the production level of vegetables. In this context, this study was conducted in order to explore the information deficiency among farmers regarding production of vegetables. Following objectives were studied in this study;

- To explore the demographic attributes of the farmers

- To investigate the total cropped area of the farmers under vegetables 
- To explore the purpose of the vegetables cultivation as perceived by the farmers

- To examine the preferred information sources of the farmers

- To assess the level of information deficiency among farmers with special references to production of the vegetables

\section{METHODOLOGY}

\section{Study area}

The study was conducted in peri-urban areas of Faisalabad, Faisalabad, "the Manchester of Pakistan" having big textile units is an important district of the Punjab province. It is the third largest city of Pakistan after Karachi and Lahore. With respect to agricultural production both in crops and livestock sectors, it is blessed with productive irrigated land. With respect to vegetable production, Faisalabad was selected as study area because most of the vegetables are cultivated in peri-urban areas across the Faisalabad (Government of Pakistan, 2006). FAO (2000) defined the peri-urban area;

"it is neither entirely urban nor purely rural in the traditional sense; it is almost the partly urbanized rural area"

The Faisalabad Bypass which is constructed around the city to let through traffic flow without interference from local traffic and is almost $15-20 \mathrm{~km}$ away from the main city was considered as the end point of peri-urban area.
Therefore, the areas falling between Faisalabad city and Bypass were selected for the study. Farmers growing vegetables in peri- 43 urban areas of Faisalabad served as study population.

\section{Selection of sample}

A complete list of registered vegetables growers (sampling frame) was obtained from the office of Fruit and Vegetable Development Project (F\&VDP), Faisalabad. According to the Table developed by FitzGibbon and Morris (1987) for determining the sample size, sample size of 208 vegetable growers was drawn through random sampling technique.

\section{Selection of vegetables}

There are many vegetables grown in peri-urban areas of Faisalabad but on the basis of the dominancy of vegetables with respect to area and production, the study focused on the training needs assessment relating to three vegetable crops i.e Cauliflower, Radish, and Turnip (Table 1).

\section{Data Collection and analysis}

A comprehensive interview schedule was prepared and used as research instrument for data collection. The data were collected through face-to-face interviews. Collected data were analyzed using Statistical Package for Social Sciences (SPSS). The rank order was determined on the basis of the mean values.

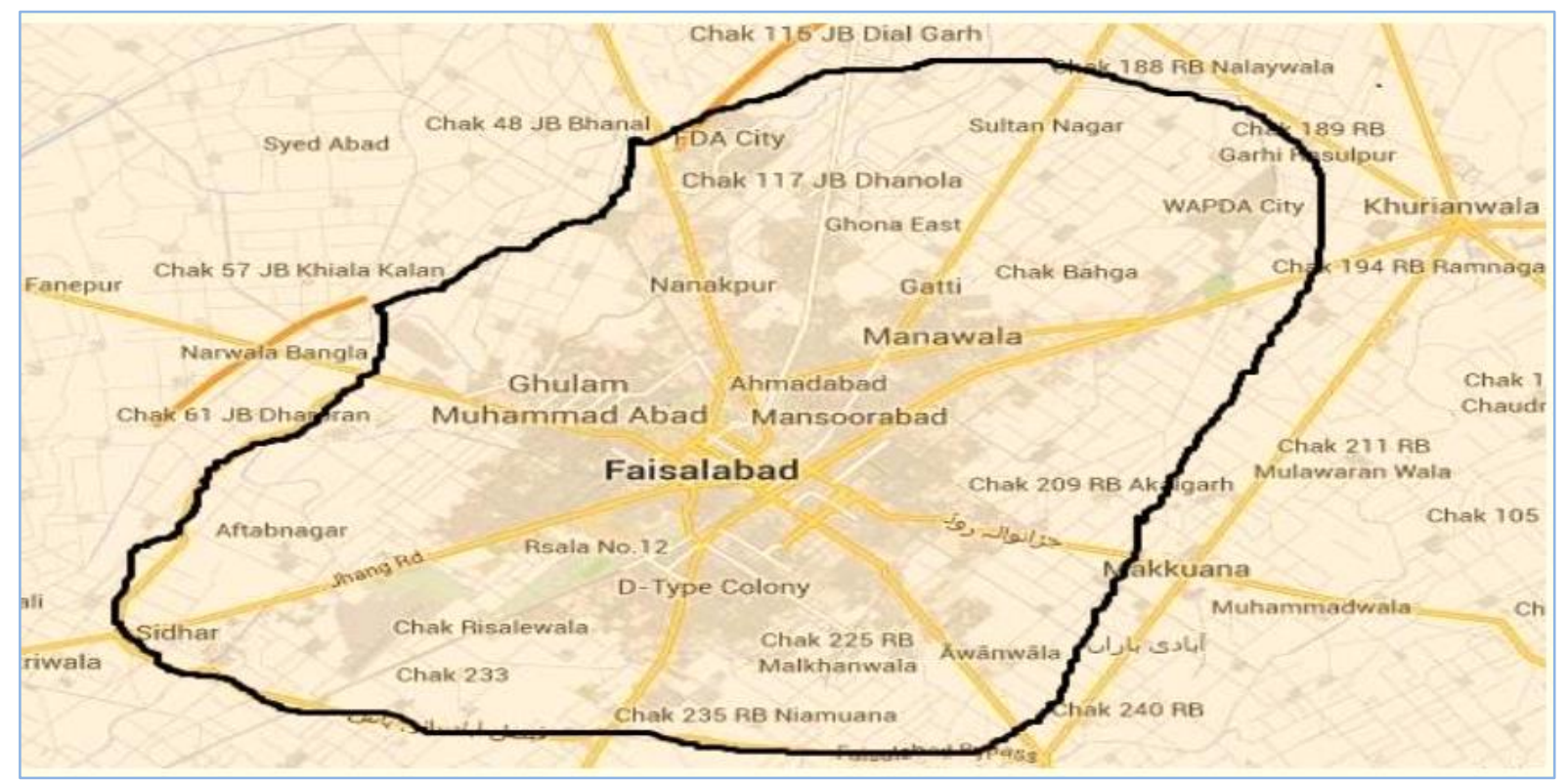

Figure 1. Map of district Faisalabad. 
Table 1. Major vegetables cultivated in Faisalabad.

\begin{tabular}{lcc}
\hline Vegetable & Area in acres & Production in tons \\
\hline Garlic & 525 & 1607 \\
Tomato & 418 & 2309 \\
Turnip & 1655 & 13899 \\
Carot & 585 & 4585 \\
Cauliflower & 1030 & 8958 \\
Peas & 295 & 782 \\
Spinach & 650 & 3809 \\
Cabbage & 325 & 2196 \\
Sweet Potato & 120 & 806 \\
Radish & 700 & 5330 \\
\hline
\end{tabular}

Crop Reporting Service, Punjab, 2013

\section{RESULTS AND DISCUSSION}

This section portrays the major findings of the study under different sections such as (i) demographic profile of the respondents (ii) Total cropped area under vegetables (iii) Purpose of growing vegetables (iv) information sources used by the farmers and (v) Information deficiency regarding vegetable production practices as perceived by the respondents. The detailed description of the demographic attributes is given in Figure 2.

\section{Demographic profile of the respondents}

The demographic attributes of the farmers included age, education, land size, tenancy status, farming experience and annual income of the farmers. Demographic characteristics of respondents are directly/indirectly related to bring change to the farmers behaviour. These characteristics not only affect the behavior of respondents but also have significant impact on decision making of farmers in order to source information from different sources (Bashir and Albarbarawi, 2011; Ashraf et al., 2015). Identified demographic characteristics are displayed in Figure 2.

\section{Age}

Figure 2 shows that one fifth of respondents $(20.2 \%)$ were aged less than 35 years. More than half (52.4\%) of respondents fell into age backet of 36-50 years followed by slightly greater than one fourth respondents $(27.4 \%)$ aged more than 50 years. These farmers were considerably older as compared to first two categories of the age.

\section{Educational level}

Of the total respondents, $52.4 \%$ had no formal schooling (illiterate) whereas $57.6 \%$ of farmers had formal schooling (literate) (Figure 2). The findings indicate that educational level among the farmers in the study area was not so good. The ratio of literate and illiterate was just nominal. Among literate farmers, 13.9, 11.1, and $9.6 \%$ of farmers had primary, primary to middle and middle to matric level of education. More than one tenth (13\%) of respondents had the highest level of education, more than matriculation. This refers to the fact that $13 \%$ of farmers had more than 10 years of schooling in the study area.

\section{Land Size}

Among total respondents, $52.4 \%$ of farmers had less than 6 acres of land in their possession followed by $34.1 \%$ of farmers having land size between $6-12$ acres (Figure 2). It can be deducted that majority of the participating farmers was small farmers. However, $13.5 \%$ of farmers in the area had considerably large land holding size, more than 12 acres. These large land holders might have more knowledge and information as compared to small farmers, who usually had less risktaking abilities in farming.

\section{Tenancy}

Among total participating farmers, more than half (56.3\%) were the owners of their land (Figure 2). Tenants were $12 \%$ in total while $31.7 \%$ of farmers were owner-cum-tenants. Almost one third percentage of owner-cum-tenants is a notion that farming is among the top priorities of the farmers. This inclination could have enabled the farmers to have great know how about the vegetable's cultivation. 


\section{Farming Experience}

As for as vegetables cultivation was concerned, more than one fourth $(27.9 \%)$ of respondents had less than 10 years of experience (Figure 2). Of the total respondents, $38 \%$ had experience between $10-20$ years and $34.1 \%$ of farmers experience surpassed over 20 years. Experience is one of the key indicators of knowledge development and with the increase in experience the farmers might have get more access to information regarding production technologies of the vegetables.

\section{Income sources}

Farming was the key income source for the participating farmers as $77.9 \%$ farmers reported. Slightly greater than one fifth $(22.1 \%)$ of respondents were generating income from non-farming sources (Figure 2).

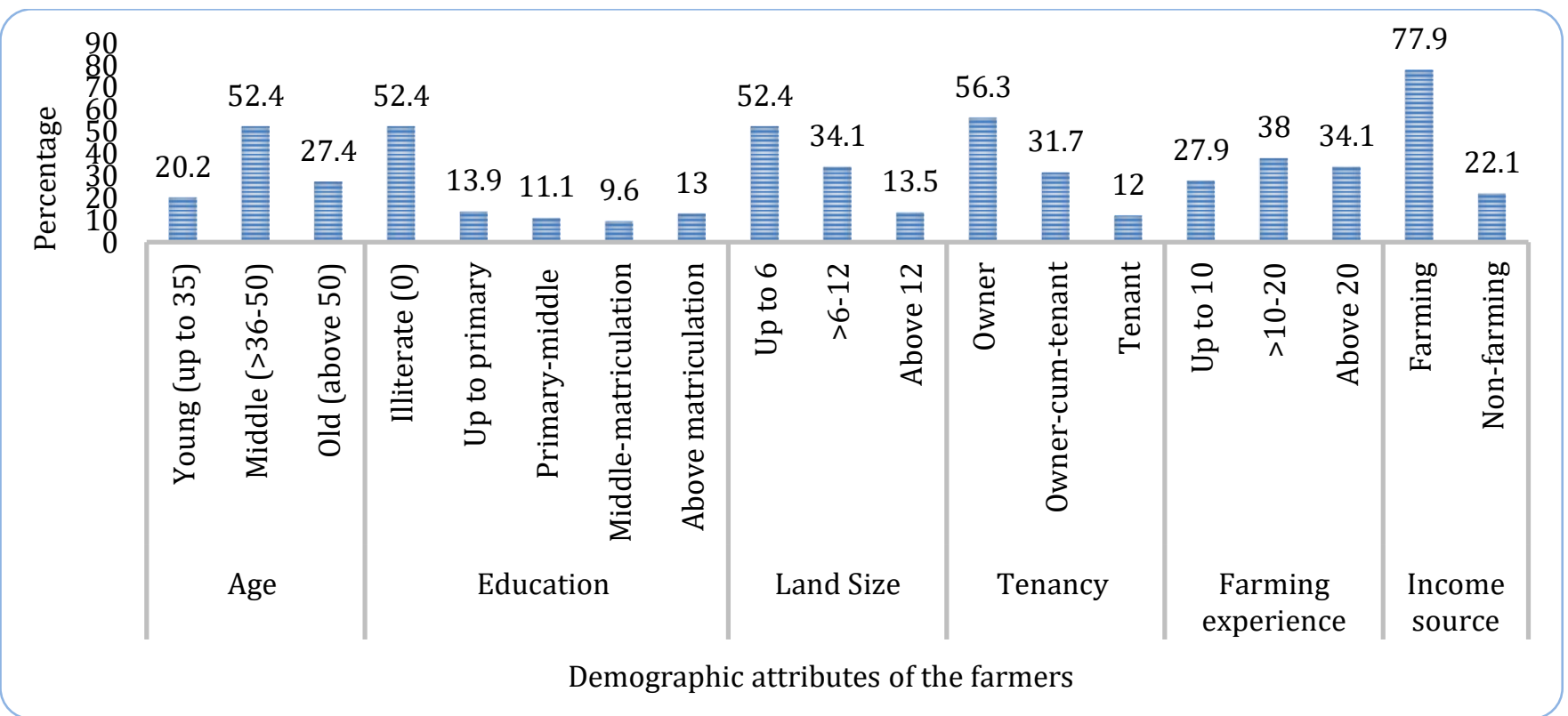

Figure 2. Demographic profile of the farmers.

\section{Total cropped area under vegetables}

This section refers to the total cropped area where the farmers had cultivation of vegetables. In this study, farmers were inquired about three vegetables i.e. Cauliflower, Turnip and Redish, as these three vegetables were ranked top among the vegetables area cultivated in Faisalabad. The area was asked in acres and the data in this regard are mentioned in Table 2.

Table 2 indicates the total cropped area under different vegetables as reported by the farmers. Cauliflower was one of the important vegetables and $42.3 \%$ of farmers had its cultivation on 1-2 acres followed by $39 \%$ of farmers cultivating cauliflower on 2-4 acres. Cauliflower was cultivated on more than 4 acres by $17.7 \%$ of farmers. Regarding Turnip, $28.8 \%$ of farmers had cultivation on $1-2$ acres and $52.4 \%$ of farmers had its cultivation on 2-4 acres. Less than one fifth $(18.8 \%)$ of respondents had cultivation on more than 4 acres. Radish, another important vegetable was cultivated on
1-2 acres by $35.6 \%$ of farmers. Of the total farmers, $45.2 \%$ had cultivation on $2-4$ acres followed by $19.2 \%$ of farmers claimant of cultivating radish on more than 4 acres of land.

It is deducted from the findings that vegetables were being cultivated primarily on small land holdings. This is accentuated with the fact that majority of the farmers in the study area were small farmers and therefore due to land size restriction the farmers were compelled to cultivate vegetable son small land holdings.

\section{Purpose of growing vegetables}

In this section, farmers reported their purpose of cultivating different vegetables either as owner cultivators, tenants and owner cum tenants. Farmers had domestic and commercial use of vegetables; thus, it was regarded critical to dissect the percentage of farmers having inclination towards particular purpose. The data is illustrated in Figure 3. 
Table 2. Area under vegetable cultivation.

\begin{tabular}{lcccccc}
\hline Area (acres) & \multicolumn{9}{c}{ Vegetables } \\
\cline { 2 - 7 } & \multicolumn{2}{c}{ Cauliflower } & \multicolumn{2}{c}{ Turnip } & \multicolumn{2}{c}{ Radish } \\
\cline { 2 - 7 } & f. & $\%$ & f. & $\%$ & f. & $\%$ \\
\hline $1-2$ & 88 & 42.3 & 60 & 28.8 & 74 & 35.6 \\
$>2-4$ & 83 & 39.0 & 109 & 52.4 & 94 & 45.2 \\
Above 4 & 37 & 17.7 & 39 & 18.8 & 40 & 19.2 \\
\hline Total & 208 & 100.0 & 208 & 100.0 & 208 & 100.0 \\
\hline
\end{tabular}

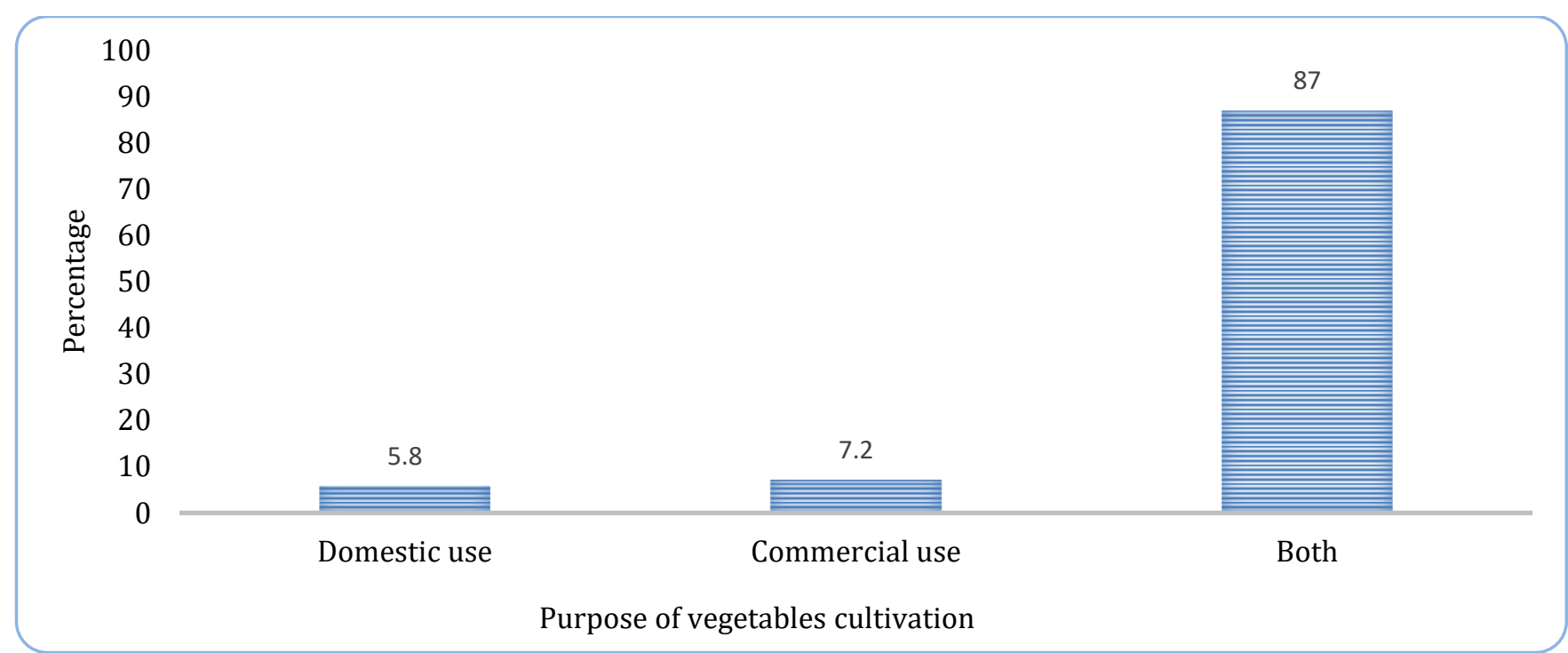

Figure 3. Purpose of growing vegetables.

Figure 3 indicates that, for the $87 \%$ of farmers the purpose of cultivating different vegetables was to consume domestically and commercialize as well in order to generate income. Of the total respondents, 5.8\% farmers were cultivating vegetables to only meet their domestic requirements followed by $7.2 \%$ of farmers who had cultivation of vegetables just to commercialize and earn income. During informal discussion, the respondents opined that healthy life requires nutritious vegetables and they thought it more convenient to grow their own vegetables for their domestic use. At least, these vegetables would be healthy and safe for the health as we applied minimum level of chemicals.

\section{Information sources used by the farmers}

In this section of the study, farmers were inquired to explore their preferred information sources. Information is central for the farmers for many reasons and therefore farmers are found using different information sources. Farmers reported with their preference and the data in this regard is illustrated in Figure 4. Figure 4 illustrates that; farmers were more reliant on neighbour farmers to access the information. According to the data, 59.61\% of farmers preferred accessing information from neighbour farmers, who had more experiences in farming. Findings are similar to those of Khooharo et al. (2008) and Chaudhry et al. (2008) as they found that farmers were inclined towards fellow farmers in order to access the required information.

Slightly greater than one-fourth $(26.44 \%)$ of the respondents, accessed information from television, which is one of the profound electronic media tools. Almost, $12 \%$ of the respondents sourced information through printed material. This limited inclination towards printed material was subject to literacy rate among farmers. This study has already pointed in the section demographic attributes that educational level among the respondents was just ordinary as $52 \%$ of farmers had no formal schooling. Of the total respondents, radio was the information source for $15 \%$ 
of respondents followed by $10.57 \%$ of farmers who were accessing information from the public sector agriculture department. This implies that one in ten respondents was accessing information from agriculture department and it is quite concerning for the working efficiency of the agriculture field staff. Agricultural field staff is termed as change agents and frontline workers. Agriculture helpline was accessed by $8.48 \%$ of farmers in order to outsource information regarding production practices of the vegetables.

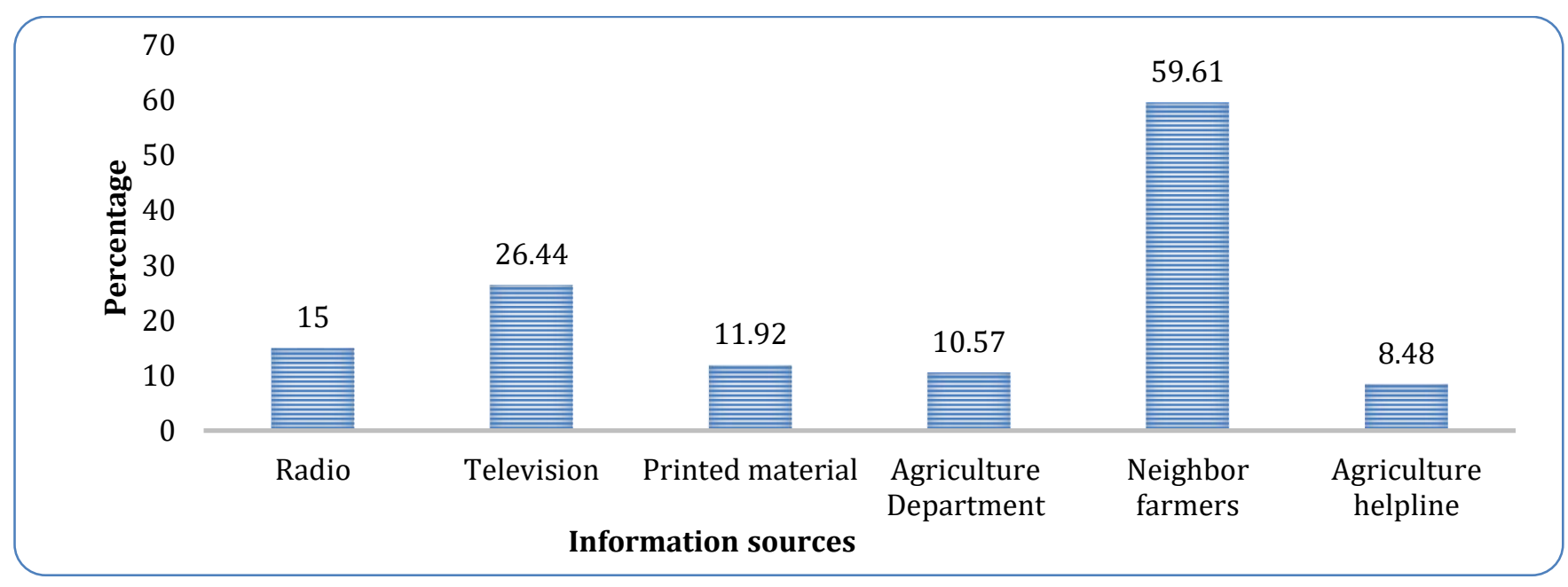

Figure 3. Information sources used by the farmers to access information.

\section{Information deficiency regarding vegetable production practices}

Awareness regarding improved and site-specific technologies of vegetables cultivation enables growers to document enhanced production and better returns. Therefore, awareness holds significant importance in agricultural process and agricultural extension is a vital force rendering information on different aspects. Elizabeth and Zira (2009) have documented high level of awareness among vegetables growers in result of extension activities. Due to this enhanced awareness interest of farmers was found increasing towards vegetables cultivation (Bhushan et al., 2015). Furthermore, considering the significance of awareness, Patil et al. (2012) recommended urgent need to educate vegetables growers through diversified extension approaches for the achievement of production potential. Considering the vitality of the information, farmers were inquired to unveil the information deficiency that they were having particularly in context of production practices if different vegetables.

In order to determine the information gap, the existing knowledge of vegetable growers regarding recommended vegetable production practices was subtracted from 100. The data obtained were then divided into five categories i.e. Very low (0-20\%), Low
(21-40\%), Medium (41-60\%), High (61-80\%), High (81$100 \%)$. Afterword, the mean values were calculated to interpret and explain the information deficiency. The data in this context is placed in Table 3. Farmers were also asked to indicate the areas in which they assume themselves deficient which ultimately affect their production. According to the findings, information deficiency regarding fertilizer application appeared at the top. The mean value 4.38 is heading towards very high which infer that awareness deficiency was at its extreme. Information deficiency regarding seed rate to get proper plant population was ranked 2 nd with mean value of 4.25. The mean value is slightly heading towards very high level of deficiency but closer to high level of deficiency. In both ways, this deficiency supposed to affect production significantly as if plant population is less in number then production will be on decline. Another deficiency revealed by the farmers was inability of insects/pests and diseases' identification. These findings are in contrast to those of Banjo et al. (2003) who revealed that farmers were quite aware of insects/pests of vegetables in Nigeria. During informal discussion farmers were of the view that due to limited awareness of identification the control of insect/pests was surging downward. Farmers were not capable of effective management of insect/pests and diseases 
despite a significant production loss was pertinent to inset/pests and diseases' outbreak. Meitei and Devi (2009) revealed that growers require information regarding almost each step involved in production process i.e. seeds, sowing, fertilizers application etc.

Information deficiency regarding other aspects involved in production system i.e varieties selection, harvesting techniques, insect pest's management, application of irrigation, plant population maintenance, land preparation, seed selection and transplanting of nursery appeared with mean value ranging from 3.00 to 3.87 indicating deficiency of medium level. Other associated aspects like sowing methods, nursery raising and sowing time were the least deficient areas ranked 12th, 13th and 14th. During discussion farmers revealed that because of common practices and experience in vegetables cultivation, sowing methods, nursery raising and sowing time were widely known to the farmers.

Table 3. Information deficiency regarding vegetable production practices.

\begin{tabular}{|c|c|c|c|c|c|c|c|c|c|c|c|}
\hline \multirow[t]{3}{*}{ Specific Areas } & \multicolumn{11}{|c|}{ Information deficiency regarding vegetable production practices } \\
\hline & \multicolumn{2}{|c|}{ Very Low } & \multicolumn{2}{|c|}{ Low } & \multicolumn{2}{|c|}{ Medium } & \multicolumn{2}{|c|}{ High } & \multicolumn{2}{|c|}{ Very High } & \multirow[t]{2}{*}{ Mean \pm SD } \\
\hline & f & $\%$ & $\mathrm{f}$ & $\%$ & $\mathrm{f}$ & $\%$ & $\mathrm{f}$ & $\%$ & $\mathrm{f}$ & $\%$ & \\
\hline Land Preparation & 8 & 3.8 & 32 & 15.4 & 108 & 51.9 & 45 & 21.6 & 15 & 7.2 & $3.13 \pm 0.894$ \\
\hline Varieties & 14 & 6.7 & 22 & 10.6 & 32 & 15.4 & 50 & 24 & 90 & 43.3 & $3.87 \pm 1.267$ \\
\hline Seed selection & 10 & 4.8 & 35 & 16.8 & 95 & 45.7 & 60 & 28.8 & 8 & 3.8 & $3.10 \pm 0.892$ \\
\hline Sowing method & 90 & 43.3 & 75 & 36.1 & 33 & 15.9 & 10 & 4.8 & 0 & 0.0 & $1.82 \pm 0.869$ \\
\hline Seed rate & 5 & 2.4 & 8 & 3.8 & 40 & 19.2 & 33 & 15.9 & 122 & 58.7 & $4.25 \pm 1.046$ \\
\hline Sowing time & 140 & 67.3 & 65 & 31.3 & 3 & 1.4 & 0 & 0.0 & 0 & 0.0 & $1.34 \pm 0.505$ \\
\hline Nursery raising & 141 & 67.8 & 35 & 16.8 & 27 & 13.0 & 5 & 2.4 & 0 & 0.0 & $1.50 \pm 0.811$ \\
\hline Transplanting & 25 & 12.0 & 39 & 18.8 & 80 & 38.5 & 40 & 19.2 & 24 & 11.5 & $3.00 \pm 1.153$ \\
\hline Fertilizer application & 2 & 1.0 & 11 & 5.3 & 15 & 7.2 & 57 & 27.4 & 123 & 59.1 & $4.38 \pm 0.904$ \\
\hline $\begin{array}{l}\text { Maintenance of plant } \\
\text { population }\end{array}$ & 3 & 1.4 & 28 & 13.5 & 123 & 59.1 & 25 & 12.0 & 29 & 13.9 & $3.24 \pm 0.905$ \\
\hline Irrigation application & 8 & 3.8 & 21 & 10.1 & 98 & 47.1 & 33 & 15.9 & 48 & 23.1 & $3.44 \pm 1.071$ \\
\hline $\begin{array}{l}\text { Insect/pests/diseases } \\
\text { identification }\end{array}$ & 10 & 4.8 & 23 & 11.1 & 37 & 17.8 & 23 & 11.1 & 115 & 55.3 & $4.01 \pm 1.270$ \\
\hline Insect pest's management & 5 & 2.4 & 43 & 20.7 & 31 & 14.9 & 94 & 45.2 & 35 & 16.8 & $3.53 \pm 1.072$ \\
\hline Harvesting & 33 & 15.9 & 22 & 10.6 & 21 & 10.1 & 47 & 22.6 & 85 & 40.9 & $3.62 \pm 1.492$ \\
\hline
\end{tabular}

\section{CONCLUSIONS AND RECOMMENDATIONS}

Vegetable's cultivation and production is critical in many ways. Apart from the consumption side, the economic prospects of the vegetable's cultivation cannot be ignored. Perhaps, for the economic reasons' farmers are found cultivating vegetables to commercialize the produce and earn capital for their livelihoods. Achieving targeted production stays as the major concern of farmers deemed dependent on various avenues including information access and availability of information. In the study area vegetable growers were highly deficient in information regarding fertilization application, seed rate, insect/pests' diseases' identification and selection of varieties. These factors are of crucial concern in terms of vegetable production. This information deficiency would have decreased the production and quality of vegetables. Therefore, it is indispensable to turn farmers information rich through different communication approaches. Currently the farmers had more reliance on traditional information sources such as neighbour farmers. This over reliance, sometime seems developing untrust on information received from the neighbour farmers and the criticism also emerged on role of agricultural extension in this regard. Therefore, agricultural extension sector should re-consider their working in the study area and should foster their communication mechanism. The integration of modern gadgets from Information Communication Technologies could be effective for the farmers and might be alternative for the farmers to use instead of neighbour farmers. This study also recommends to the future researchers to investigate the role of neighbour farmers in information delivery and how it can be improved or mainstreamed. 


\section{REFERENCES}

Adil, S. A., M. W. A. Chattha, K. Bakhsh and S. Hassan. 2007. Profitability analysis of summer vegetables by farm size. Pakistan Journal of Agricultural Sciences, 44: 184-88.

Adil, S. A., A. Maqsood, K. Bakhsh and S. Hassan. 2012. Forecasting demand and supply of onion in Pakistani Punjab. Pakistan Journal of Agricultural Sciences, 49: 205-10.

Ashraf, S., G. A. Khan, S. Ali and M. Iftikhar. 2015. Socioeconomic determinants of the awareness and adoption of citrus production practices in Pakistan. Ciência Rural, 45: 1701-06.

Banjo, A. D., O. A. Lawal, O. E. Fapojuwo and E. A. Songonuga. 2003. Farmers knowledge and perception of horticultural insect pest problems in southwestern Nigeria. African Journal of Biotechnology, 2: 434-37.

Bashir, M. S. and S. A. Albarbarawi. 2011. Factors Influencing the Adoption of Self Service Technologies (SSTs): A study of attitudes towards SSTs (Internet Banking, Online Shopping and Self-Check-In Machine at the Airports) and the influence of new technologies (smart phones and tablet computers): (Dissertation). Retrieved from http://urn.kb.se/resolve?urn=urn:nbn:se:umu: diva-49279\}.

Chaudhry, K., S. Muhammad, A. Saghir and I. Ashraf. 2008. Rural women's access to various sources of information in tehsil Faisalabad. Journal of Animal and Plant Sciences, 18: 99-101.

Department of Economic and Social Affairs. 212. World urbanization prospects, the 2011 revision. Population Division, United Nations, New York.

Elizabeth, S. and D. Y. Zira. 2009. Awareness and effectiveness of vegetable technology information packages by vegetable farmers in Adamawa State, Nigeria. African Journal of Agricultural Research, 4: 065-70.

FAO. 2000. Defining the peri-urban: rural-urban linkages and institutional connections. 0251-1894, 8- 26.

Fitz-Gibbon, C. T. and L. L. Morris. 1987. How to design a program evaluation Sage.

Gebru, B., M. Yared and N. Gebremichael. 2017. Sources of information and information seeking behavior of smallholder farmers of Tanqa Abergelle Wereda, central zone of Tigray,
Ethiopia. Journal of Agricultural Extension and Rural Development, 9: 47-52.

Government of Pakistan. 2006. Pre-feasibility study for fruit and vegetable zones in Karachi, Multan, Faisalabad, Swat and Quetta.

Government of Pakistan. 2012. Economic survey of Pakistan. Economic Advisor's Wing, Finance Division, Islamabad. .

Hall, J. N., S. Moore, S. B. Harper and J. W. Lynch. 2009. Global Variability in Fruit and Vegetable Consumption. American Journal of Preventive Medicine, 36: 402-09.e5.

Khokhar, M. 2014. Production status of major vegetables in Pakistan, their problems and suggestions. Agric. Corner, 9.

Khooharo, A., R. Memon and M. Lakho. 2008. An assessment of farmers' level of knowledge about proper usage of pesticides in Sindh Province of Pakistan. Sarhad Journal of Agriculture, 24: 53139.

Knapton, S. 2014. Healthy diet means 10 portions of fruit and vegetables per day, not five. (Online) http://www.telegraph.co.uk/news/science.

Meitei, L. S. and T. Devi. 2009. Farmers information needs in rural Manipur: an assessment. Annals of Library and Information Studies, 56: 35-40.

Memon, N. 2013. Vegetable Exports from Pakistan. Available on: http://www. foodjournal. pk/JanFeb-2013/PDF-JanFeb-2013/Exclusive-articleDr-Noor. pdf.

Midmore, D. J. and H. G. P. Jansen. 2003. Supplying vegetables to Asian cities: is there a case for peri-urban production? Food Policy, 28: 13-27.

Otitoju, G., H. Ene-Obong and O. Otitoju. 2014. Macro and micro nutrient composition of some indigenous green leafy vegetables in south-east zone nigeria. Journal of Food Processing \& Technology, 5: 1.

Patil, M., S. Patil, R. Rahane and S. Bhosale. 2012. Effect of technology adoption on onion production in Maharashtra. Trends in life Sciences, 1: 53-56.

Rao, A. and L. Rao. 2007. Carotenoids and human health. Pharmacological Research, 55: 207-16.

Shaheen, S., M. Sial, G. Sarwar and R. Munir. 2011. Nexus between human capital and technical efficiency of cauliflower growers in soon valley, Punjab: A panel data analysis. International Journal of Humanities and Social Science, 1: 129-35. 
Stangeland, T., S. F. Remberg and K. A. Lye. 2009. Total antioxidant activity in 35 Ugandan fruits and vegetables. Food Chemistry, 113: 85-91. 